\title{
Solitons in normal Fermi liquid
}

\author{
G.M. Peradze and N.L. Tsintsadze \\ Faculty of Exact and Natural Sciences and Andronikashvili Institute of Physics \\ Javakhishvili Tbilisi State University, Tbilisi 0128, Georgia \\ E-mail: nltsin@yahoo.com
}

Received June 6, 2018, revised August 9, 2018, published online November 26, 2018

\begin{abstract}
To be based on the new quantum kinetic equation of Fermi particles, which recently was derived by N.L. Tsintsadze and L.N. Tsintsadze, a general quantum dispersion equation for almost ideal Fermi gas is derived and studied for some interesting cases. Here we consider only pair interactions between particles and we used energy expression derived by V.M. Galitski in the ordinary perturbation theory, which involves only the scattering amplitude. New effect that we have shown is that novel quantum term (Madelung term) in the kinetic equation leads to the formation of rarefaction solitary waves in neutral Fermi liquid. Furthermore, attraction and repulsion between particles have tendency to change rarefaction solitary wave speed and shape: Attraction between particles increases rarefaction soliton speed and amplitude, repulsion decreases soliton speed and amplitude.
\end{abstract}

Keywords: Fermi liquid, quasiparticle interaction, solitary wave.

In recent years, a huge number of works have been devoted to the investigation of collective behavior of quantum Fermi gas. It is well known that at temperatures $1-2 \mathrm{~K}$ only two neutral quantum liquids exist in nature, the isotopes of helium ${ }^{3} \mathrm{He}$ and ${ }^{4} \mathrm{He}$, all other substances solidify. The reason for helium to remain liquid is weak interaction between its atoms. Based on this fact Landau has created the theory of Fermi liquid [1]. In which he took into account only the weakly excited energy levels of the liquid, lying fairly close to the ground state assuming that any weakly excited state of a macroscopic body can be represented as an assembly of separate elementary excitation (quasiparticles). This elementary excitation are represented as the collective motion of atoms in liquid and it can not be represented as excitation of individual atoms.

Landau's theory of Fermi liquids was generalized by incorporation the De Broglie waves diffraction [2] (Madelung term in the kinetic equation) and it was shown that zero sound waves can exist even in the ideal Fermi gas [3]. Alkhanishvili and Tsintsadze [4] have developed quasilinear theory of Fermi liquids by taking into account the diffraction of De Broglie waves.

We want to study properties of almost ideal Fermi gas following the method discussed in [1]. We shall consider here only a pair interaction between particles, since triple collisions contribute to energy only in a higher approximation, and assume for simplicity that the interaction $U(\mathbf{r})$ is independent of particle spin. In the limitin case of slow collisions, the mutual scattering amplitude of particles with mass $m$ tends to a constant limit $a=m U_{0} / 4 \pi \hbar^{2}$, that is called scattering length, where $U_{0}=\int U(\mathbf{r}) d \mathbf{r}$.

Using diagram technique, V.M. Galitski [5] calculated the quasiparticle energy spectrum of almost ideal Fermi gas in the ordinary perturbation theory and derived energy expression which involves only the scattering amplitude:

$$
\varepsilon(p)=\frac{p^{2}}{2 m}+\frac{2 \pi \hbar^{2} a n}{m} .
$$

This limit correspond to the $s$ state of the pair of particles (with spin 1/2).

In this article we discuss some properties of slightly non-ideal Fermi gas with repulsion $(a>0)$ or attraction $(a<0)$ between the particle. At first sight, the calculations given there are equally valid whether there is attraction or repulsion, i.e., whether the scattering length is positive or negative. In fact, however, for the case of attraction the ground state of the system is unstable. The physical nature of this instability consists in a tendency of particles to "pair" by forming bound states of pair of particles lying near the Fermi surface in $p$-space and having equal and anti parallel spins (the Cooper effect [6]).

First we shall derive hydrodynamic equations. We use novel quantum kinetic equation for Fermi particles [2]. This equation incorporates quantum term, that contains all the information on the quantum effects. This novel quantum Madelung term is placed into the force expression in the Vlasov kinetic equation 


$$
\frac{\partial f}{\partial t}+(\mathbf{v} \nabla) f+\frac{d \mathbf{p}}{d t} \frac{\partial f}{\partial \mathbf{p}}=0
$$

where $\frac{d \mathbf{p}}{d t}=-\nabla \varepsilon+\frac{\hbar^{2}}{2 m} \nabla \frac{1}{\sqrt{n}} \Delta \sqrt{n}$ for neutral Fermi liquid.

With relation (1) corresponding kinetic equation has form

$$
\begin{gathered}
\frac{\partial f}{\partial t}+(\mathbf{v} \nabla) f-\frac{2 \pi \hbar^{2} a}{m} \nabla n \frac{\partial f}{\partial \mathbf{p}}+ \\
+\frac{\hbar^{2}}{2 m} \nabla \frac{1}{\sqrt{n}} \Delta \sqrt{n} \frac{\partial f}{\partial \mathbf{p}}=0 .
\end{gathered}
$$

Following standard method, we construct hydrodynamic equations from last formula and get equation of continuity and motion for macroscopic quantities

$$
\begin{gathered}
\frac{\partial N}{\partial t}+\nabla(N \mathbf{u})=0, \\
\frac{\partial \mathbf{u}}{\partial t}+(\mathbf{u} \nabla) \mathbf{u}+\frac{\varepsilon_{F}}{m} \nabla(N)^{2 / 3}+ \\
+\nabla\left(\frac{2 \pi \hbar^{2} a n_{0}}{m^{2}} N-\frac{\hbar^{2}}{2 m^{2}} \frac{1}{\sqrt{N}} \Delta \sqrt{N}\right)=0,
\end{gathered}
$$

where for the pressure term we used

$$
P=\left(3 \pi^{2}\right)^{2 / 3} \hbar^{2} n^{5 / 3} /(5 m)
$$

and therefore $\nabla P / n m=\frac{\varepsilon_{F}}{m} \nabla\left(n / n_{0}\right)^{2 / 3}, N=n / n_{0}$ and $u$ is macroscopic velocity of Fermi liquid and

$$
u=\frac{1}{n} \int \frac{2 d p^{3}}{(2 \pi \hbar)^{3}} \mathbf{v} f(\mathbf{r}, \mathbf{p}, t) .
$$

Last term in Eq. (5) describes the dispersive effects. If we neglect dispersive terms in Eq. (5), then those equations reduce to the Euler equations.

Obviously after linerization hydrodynamic equations (4) and (5) with respect of $u=\delta u$ and $N=1+\delta N$, where $\delta u$ and $\delta N$ is proportional to $\exp [-i(\mathbf{k r}-\omega t)]$, we obtain dispersion relation

$$
\omega^{2}=\left(\frac{2 \pi \hbar^{2} a n_{0}}{m^{2}}+\frac{2 \varepsilon_{F}}{3 m}\right) k^{2}+\frac{\hbar^{2}}{4 m^{2}} k^{4} .
$$

Last term in the dispersion equation (6) is due to the diffraction term (this is the Madelung term), i.e., is completely quantum term. We can conclude that the sound wave dispersion relation in ${ }^{3} \mathrm{He}$ coincides with the Bogoliubov spectrum obtained for quantum Bose liquids.

We now consider nonlinear one dimensional traveling waves in a single direction, so-called simple waves. For simple waves it is well known that for the waves with any amplitude, velocity can be expressed as the function of the density $u=u(N)$. From Eqs. (5) (without dispersive term) and (4) then follows for a wave propagating in the positive $x$ direction

$$
\begin{gathered}
\frac{\partial u}{\partial N}=\sqrt{\frac{1}{N}\left(\frac{2 \pi \hbar^{2} a n_{0}}{m^{2}}+\frac{2 \varepsilon_{F}}{3 m N^{1 / 3}}\right)} ; \\
N=\left[\frac{1}{A}\left(\frac{u A}{2}+\left(A+\frac{v_{F}^{2}}{3}\right)^{3 / 2}\right)^{2 / 3}-\frac{v_{F}^{2}}{3 A}\right]^{3},
\end{gathered}
$$

here $A=2 \pi \hbar^{2} a n_{0} / m^{2}$ and $A$ can have both positive and negative sign as $a$. We used initial condition: $N=N_{0}=1$, $u=0$.

To simplify density expression we use fact that $v_{F}^{2} /(3 A) \gg 1$. It is clearly seen from the energy expression (1): As we know last term is energy correction and therefore is smaller than first term on the RHS. Simplified expression is

$$
N=\left[1+\frac{u}{\sqrt{3} v_{F}}\left(1-\frac{3 A}{2 v_{F}^{2}}\right)\right]^{3} .
$$

From this expression it is clear that when we have attraction between particles: $A<0$, density increases, and in the opposite case when we have repulsion $A>0$, density decreases. In the limit, when $A$ goes to zero, we see that $N=1+\sqrt{3} u / v_{F}$. This relation can also be derived from equation (7) without first term in the root, on the RHS.

Since the velocity $u$ is the function of density, therefore it is different for the different points of the wave profile, i.e., the profile changes in the course of time. One can see from Eq. (7) that $d u / d n>0$, i.e., the velocity of propagation of a given point at the wave profile increases with density. This is the condition for the shock waves [7-9].

In order to derive Korteweg-de Vries (KdV) equation for one dimensional case, we insert density expression (9) into the equation of motion (5):

$$
\begin{gathered}
\frac{\partial u}{\partial t}+\frac{\partial u}{\partial x}\left(u\left(\frac{4}{3}-\frac{A}{v_{F}^{2}}\right)+\frac{v_{F}}{\sqrt{3}}-\frac{\sqrt{3} A}{2 v_{F}}\right)- \\
-\frac{\sqrt{3} \hbar^{2}}{4 v_{F} m^{2}} \frac{\partial^{3} u}{\partial x^{3}}=0 .
\end{gathered}
$$

We introduce new variables

$U_{0}=v_{F} / \sqrt{3}-\sqrt{3} A / 2 v_{F}, \xi=x-U_{0} t, V=u\left(4 / 3-A / v_{F}^{2}\right)$, $\beta=-\sqrt{3} \hbar^{2} /\left(4 v_{F} m^{2}\right)$ and rewrite Eq. (10) as

$$
\frac{\partial V}{\partial t}+V \frac{\partial V}{\partial \xi}+\beta \frac{\partial^{3} V}{\partial \xi^{3}}=0 .
$$


We are interested in solutions which describe waves with stationary profile. For such waves velocity $V(t, \xi)$ depends only on the parameter $\left(\xi-V_{0} t\right)$, where $V_{0}$ is some constant and wave propagation speed is

$$
U=U_{0}+V_{0} \text {. }
$$

In our case coefficient of higher derivative is negative $(\beta<0)$ and in order to solve $\mathrm{KdV}$ equation we need to change variables as

$$
\begin{aligned}
& \xi \rightarrow-\xi ; \\
& V_{0} \rightarrow-V_{0} ; \\
& V \rightarrow-V .
\end{aligned}
$$

With such change of variables, equation remains identical except opposite sign of $\beta$. Those change does not change mathematical form of solution, but instead of "positive" (compressible), we have "negative” (rarefaction) solitary wave and the speed of such soliton is less than $U_{0}$.

We replace $\xi$ with the new variable $Z$ into $K d V$ equation (11), taking into account that $Z=\xi-V_{0} t, \partial Z / \partial t=-V_{0}$, $\partial Z / \partial \xi=1$. Here we assume that variables are changed according to (13). We change variables back in the solution

$$
-V_{0} \frac{\partial V}{\partial Z}+V \frac{\partial V}{\partial Z}+|\beta| \frac{\partial^{3} V}{\partial Z^{3}}=0
$$

This is invariant under the change

$$
V \rightarrow V+V_{C}, \quad V_{0} \rightarrow V_{0}+V_{C}
$$

with any constant $V_{C}$.

Integration two times gives

$$
|\beta|\left(\frac{\partial V}{\partial Z}\right)^{2}=-\frac{1}{3}\left(V-V_{1}\right)\left(V-V_{2}\right)\left(V-V_{3}\right),
$$

where $V_{1}, V_{2}$ and $V_{3}$ are integration constants that depend only on the initial conditions of perturbation and $V_{0}=\left(V_{1}+V_{2}+V_{3}\right) / 3$.

We are interested only bounded solutions of Eq. (16), because unlimited increasing of $V$ contradicts our assumption of slight non-linearity. This means all constants must be real. Without loss of generality we can arrange them in order: $V_{1} \geq V_{2} \geq V_{3}$. Also we can always take $V_{3}=0$ using transformation (15). Than $V$ can vary only in the range $V_{1} \geq V \geq V_{2}$.

General solution of the equation (16) is

$$
V=V_{1} \operatorname{dn}^{2}\left(\sqrt{\frac{V_{1}}{12|\beta|}} Z, s\right),
$$

where $\operatorname{dn}^{2}\left(\sqrt{V_{1} /(12|\beta|)} Z, s\right)$ is elliptic Jacobi function with modulus $s=\sqrt{1-V_{2} / V_{1}}$. Elliptic Jacobi function is periodic function with period [10]

$$
\lambda=4 \sqrt{\frac{3|\beta|}{V_{1}}} K(s),
$$

where $K(s)$ is complete elliptic integral of the first kind. We change variables back and wave propagation speed for negative $\beta$ is

$$
U=U_{0}-V_{0}\left(1-\frac{3}{2-s^{2}} \frac{E(s)}{K(s)}\right),
$$

where $E(s)$ is complete elliptic integral of the second kind.

The parameter $s(0<s<1)$ measures non-linearity. When $s \ll 1$ solution is expressed in periodic functions, $s \rightarrow 0$ solutions of Eq. (17) goes to the solution of linearized equations and for the other extreme case: $s \rightarrow 1 \lambda$ goes to infinity, i.e., we obtain solitary wave solution.

When $s \rightarrow 1, \operatorname{dn}(\alpha, s)=1 / \cosh (\alpha), E(s) / K(s)=0$ and

$$
\begin{gathered}
V=3 V_{0} \cosh ^{-2} \sqrt{\frac{V_{0}}{4|\beta|}} Z, \\
U=U_{0}-V_{0} .
\end{gathered}
$$

Constant $3 V_{0}$ is the soliton amplitude. Width is decreasing as $\sqrt{V_{0}}$ with increasing amplitude. Velocity expression is in accordance with Eq. (12) and can be rewritten as

$$
U=\frac{v_{F}}{\sqrt{3}}-\frac{\sqrt{3} A}{2 v_{F}}-V_{0} .
$$

Here $V_{0}$ also contains $A$, but only in the second approximation. Since we know that rarefaction soliton speed is less than speed of sound waves, we can check how does interaction between particles changes that fact. Speed of ordinary sound waves $U_{S}$ can be found in the dispersion relation in the first approximation: $\omega=U_{S} k$. From our dispersion relation (6) we calculate $U_{S}=v_{F} / \sqrt{3}+\sqrt{3} A / 2 v_{F}$ and therefore

$$
U-U_{S}=-\frac{\sqrt{3} A}{v_{F}}-V_{0} .
$$

If $A>0$ his difference is always negative. In the opposite case, when $A<0$ the condition for velocity difference to be positive is $V_{0}<\sqrt{3} v_{F} n_{0}^{1 / 3} a$ and it can be fulfilled for small amplitudes of solitary waves $\left(V_{0}\right)$.

In conclusion we can say when we have repulsion between particles $(A>0)$, rarefaction soliton speed is, as expected, always less than speed of sound waves. Moreover, it decreases even more because of pair interaction between particles. In the opposite case, we have attraction $(A<0)$ soliton speed increases and in the certain amplitudes can rich speed of ordinary sound waves.

To summarize, we studied how does pair interaction changes different parameters in normal, almost ideal Fermi liquid. We constructed hydrodynamic equations with Madelung term and derived $\mathrm{KdV}$ equation. We found that rarefaction solitons can propagate in almost ideal, neutral Fermi liquid and it's velocity and amplitude is dependent on the scattering length. This dependence shows only the tendency how does interaction between particles change various parameters (density, solitary wave velocity and half-width) and does not change nature of phenomenons. 
1. L.D. Landau and E.M. Lifshitz, Statistical Physics, Part 2, Chapter 6, 21. Pergamon Press, Oxford (1981).

2. N.L. Tsintsadze and L.N. Tsintsadze, EPL 88, 35001 (2009).

3. N.L. Tsintsadze and L.N. Tsintsadze, Fiz. Nizk. Temp. 37, 982 (2011) [Low Temp. Phys. 37, 782 (2011)].

4. N.L. Tsintsadze and D.M. Alkhanishvili, Fiz. Nizk. Temp. 42, 1368 (2016) [Low Temp. Phys. 42, 1071 (2016)].

5. V.M. Galitski, JETP 34, 151 (1958).

6. L.N. Cooper, Phys. Rev. 104, 1189 (1956).

7. G.B. Whitham, Linear and nonlinear waves, Chapter 13, John Wiley and Sons, New York (1974).

8. L.D. Landau and E.M. Lifshitz, Fluid Mechanics, Chapter 9, Pergamon Press, Oxford (1987).

9. V.I. Karpman, Non-Linear Waves on Dospersive Media, Chapter 4, Pergamon Press, Oxford (1975).

10. L.D. Landau and E.M. Lifshitz, Physical Kinetics, Chapter 39, Solitons in a weakly dispersing medium, Pergamon Press, Oxford (1981).

\section{Солітони в нормальній фермі-рідині}

\section{Г.М. Перадзе, Н.Л. Цінцадзе}

На підставі нового квантового кінетичного рівняння фермічастинок, нещодавно отриманого Н.Л. Цинцадзе та Л.Н. Цинцадзе, загальне квантове дисперсійне рівняння для майже ідеального фермі-газу вивчено для деяких цікавих випадків. Розглянуто тільки парні взаємодії між частинками та використано вираз для енергії, отриманий В.М. Галицьким у звичайній теорії збурень, яка включає тільки амплітуду розсіювання. Отриманий ефект полягає в тому, що новий квантовий член (терм Маделунга) в кінетичному рівнянні призводить до утворення розріджених відокремлених хвиль в нейтральній фермірідині. Більш того, притягання та відштовхування між частинками мають тенденцію до зміни швидкості й форми таких хвиль: притягання між частинками збільшує швидкість та амплітуду солітону, а відштовхування зменшує швидкість та амплітуду солітону.

Ключові слова: фермі-рідина, квазічастинкова взаємодія, солітон.

\section{Солитоны в нормальной ферми-жидкости}

\section{Г.М. Перадзе, Н.Л. Цинцадзе}

На основании нового квантового кинетического уравнения ферми-частиц, недавно полученного Н.Л. Цинцадзе и Л.Н. Цинцадзе, общее квантовое дисперсионное уравнение для почти идеального ферми-газа изучено для некоторых интересных случаев. Рассмотрены только парные взаимодействия между частицами и использовано выражение для энергии, полученное В.М. Галицким в обычной теории возмущений, которая включает только амплитуду рассеяния. Полученный эффект заключается в том, что новый квантовый член (терм Маделунга) в кинетическом уравнении приводит к образованию разреженных уединенных волн в нейтральной фермижидкости. Более того, притяжение и отталкивание между частицами имеют тенденцию к изменению скорости и формы таких волн: притяжение между частицами увеличивает скорость и амплитуду солитона, а отталкивание уменьшает скорость и амплитуду солитона.

Ключевые слова: ферми-жидкость, квазичастичное взаимодействие, солитон. 